Research

Open Access

\title{
Computer simulation allows goal-oriented mechanical ventilation in acute respiratory distress syndrome
}

\author{
Leif Uttman, Helena Ögren, Lisbet Niklason, Björn Drefeldt and Björn Jonson
}

\author{
Department of Clinical Physiology, Lund University, 22185 Lund, Sweden \\ Corresponding author: Leif Uttman, leif.uttman@med.lu.se
}

Received: 8 Jan 2007 Revisions requested: 31 Jan 2007 Revisions received: 21 Feb 2007 Accepted: 12 Mar 2007 Published: 12 Mar 2007

Critical Care 2007, 11:R36 (doi:10.1186/cc5719)

This article is online at: http://ccforum.com/content/11/2/R36

(c) 2007 Uttman et al.; licensee BioMed Central Ltd.

This is an open access article distributed under the terms of the Creative Commons Attribution License (http://creativecommons.org/licenses/by/2.0), which permits unrestricted use, distribution, and reproduction in any medium, provided the original work is properly cited.

\begin{abstract}
Introduction To prevent further lung damage in patients with acute respiratory distress syndrome (ARDS), it is important to avoid overdistension and cyclic opening and closing of atelectatic alveoli. Previous studies have demonstrated protective effects of using low tidal volume $\left(\mathrm{V}_{\mathrm{T}}\right)$, moderate positive end-expiratory pressure and low airway pressure. Aspiration of dead space (ASPIDS) allows a reduction in $\mathrm{V}_{\mathrm{T}}$ by eliminating dead space in the tracheal tube and tubing. We hypothesized that, by applying goal-orientated ventilation based on iterative computer simulation, $\mathrm{V}_{\mathrm{T}}$ can be reduced at high respiratory rate and much further reduced during ASPIDS without compromising gas exchange or causing high airway pressure.
\end{abstract}

Methods ARDS was induced in eight pigs by surfactant perturbation and ventilator-induced lung injury. Ventilator resetting guided by computer simulation was then performed, aiming at minimal $\mathrm{V}_{\mathrm{T}}$, plateau pressure $30 \mathrm{cmH}_{2} \mathrm{O}$ and isocapnia, first by only increasing respiratory rate and then by using ASPIDS as well.

Results $\mathrm{V}_{\mathrm{T}}$ decreased from $7.2 \pm 0.5 \mathrm{ml} / \mathrm{kg}$ to $6.6 \pm 0.5 \mathrm{ml} / \mathrm{kg}$ as respiratory rate increased from 40 to $64 \pm 6$ breaths $/ \mathrm{min}$, and to $4.0 \pm 0.4 \mathrm{ml} / \mathrm{kg}$ when ASPIDS was used at $80 \pm 6$ breaths/ min. Measured values of arterial carbon dioxide tension were close to predicted values. Without ASPIDS, total positive endexpiratory pressure and plateau pressure were slightly higher than predicted, and with ASPIDS they were lower than predicted.

Conclusion In principle, computer simulation may be used in goal-oriented ventilation in ARDS. Further studies are needed to investigate potential benefits and limitations over extended study periods.

\section{Introduction}

In patients with acute lung injury and acute respiratory distress syndrome (ARDS), adequate gas exchange requires mechanical ventilation; however, this can aggravate the condition by causing ventilator-induced lung injury (VILI), particularly at high tidal volume $\left(\mathrm{V}_{\mathrm{T}}\right)$ and high airway pressure [1-4]. Tidal lung collapse and re-expansion causing shear forces should be avoided [5]. Lung-protective ventilation may be based on low $\mathrm{V}_{\mathrm{T}}$, low postinspiratory plateau pressure $\left(\mathrm{P}_{\mathrm{PLAT}}\right)$ and adequate positive end-expiratory pressure (PEEP) [2-4,6]. An adequate PEEP should reduce alveolar collapse occurring at the end of expiration. A low $\mathrm{V}_{\mathrm{T}}$ prevents high $\mathrm{P}_{\mathrm{PLAT}}$ and alveolar overdistension $[7,8]$. Permissive hypercapnia, partial liquid ventilation, extracorporeal carbon dioxide removal, high-frequency oscilla- tory ventilation, tracheal gas insufflation and aspiration of dead space (ASPIDS) are strategies that have been developed to prevent VILI [9-13].

When ASPIDS is used during late expiration, a defined volume of gas (ASPIDS volume) is aspirated through a catheter from the tip of the tracheal tube and simultaneously replaced with fresh gas through the ordinary lumen of the tracheal tube. ASPIDS increases carbon dioxide removal by reducing dead space. De Robertis and coworkers [13-15] showed that ASPIDS allows decreased $V_{\mathrm{T}}$ and airway pressures in healthy animals as well as in ARDS patients. Liu and colleagues [16] used ASPIDS to lower $\mathrm{V}_{\mathrm{T}}$ in patients with exacerbation of chronic obstructive pulmonary disease, resulting in reduced

$\overline{\mathrm{ARDS}}=$ acute respiratory distress syndrome; ASPIDS = aspiration of dead space; Fio ${ }_{2}=$ fractional inspired oxygen; Paco ${ }_{2}=$ arterial carbon dioxide tension; $\mathrm{PaO}_{2}=$ arterial oxygen tension; $\mathrm{PEEP}=$ positive end-expiratory pressure; $\mathrm{P}_{\mathrm{PLAT}}=$ postinspiratory plateau pressure; $\mathrm{RR}=$ respiratory rate; $\mathrm{V}_{\mathrm{E}} \mathrm{CO}_{2}=$ expired volume of carbon dioxide; $\mathrm{V}_{1} \mathrm{CO}_{2}=$ re-inspired volume of carbon dioxide; $\mathrm{V}_{\mathrm{T}} \mathrm{CO}_{2}=$ eliminated tidal volume of carbon dioxide. 
airway pressures and arterial carbon dioxide tension $\left(\mathrm{PacO}_{2}\right)$. The potential of ASPIDS to decrease $V_{T}$ is not studied at high respiratory rates (RRs).

A critically ill patient connected to a ventilator represent a very complex system. It is virtually impossible, even for experienced physicians, to know the best combination of, for instance, $\mathrm{V}_{\mathrm{T}}$, PEEP, RR and inspiratory/expiratory ratio that leads to specific physiological goals. Such goals may be to maintain an adequate $\mathrm{PaCO}_{2}$ and a limited $\mathrm{P}_{\mathrm{PLAT}}$ at minimal $\mathrm{V}_{\mathrm{T}}$.

A tool for decision support when resetting the ventilator was previously developed $[17,18]$. In principle, that tool is based on the patient's physiological lung function profile, enabling computer simulation of mechanics and gas exchange at alternative ventilator settings. Hence, the consequences of an intended adjustment in ventilator settings may be analyzed in advance. In theory, that tool may be used iteratively in order to identify the optimal ventilator settings that will lead to predefined goals.

We tested the hypothesis that, by applying goal-orientated ventilation based on iterative computer simulation, $V_{T}$ can be reduced at high $\mathrm{RR}$ and much further reduced during ASPIDS, without compromising gas exchange or causing high airway pressure.

\section{Materials and methods Material and preparation}

The local ethics board of animal research approved the study. Eight pigs of the Swedish native breed weighing 18 to $22 \mathrm{~kg}$ were used. The animals were pre-medicated with xylazine ( 2 $\mathrm{mg} / \mathrm{kg}$ ) and anaesthetized with ketamine $(15 \mathrm{mg} / \mathrm{kg}$ ). During the experiment anaesthesia was maintained by the continuous intravenous infusion of fentanyl (60 $\mu \mathrm{g} / \mathrm{kg} \cdot$ per hour) and midazolam $(0.7 \mathrm{mg} / \mathrm{kg} \cdot$ per hour $)$. Initially the animals were hydrated with $1,000 \mathrm{ml}$ ringer acetate, followed by infusion at $100 \mathrm{ml} /$ hour. Ten millilitres of dextran 1 was infused, followed by $1,000 \mathrm{ml}$ dextran 70 to avoid falling blood pressure. A catheter in the left femoral artery allowed monitoring of heart rate and arterial blood pressure, and sampling for immediate blood gas analysis (Radiometer ABL725, Copenhagen, Denmark). Body temperature was maintained constant. The animals were intubated and ventilated (Servo Ventilator 900C; Siemens-Elema $A B$, Solna, Sweden). Carbon dioxide concentration at the airway opening was measured using a mainstream carbon dioxide analyser $\left(\mathrm{CO}_{2}\right.$ Analyzer 930; Siemens-Elema $\left.\mathrm{AB}\right)$. The ventilator/computer system used to record data and control the ventilator has been described elsewhere [19].

\section{Protocol}

Basal ventilation was volume-controlled square inspiratory flow pattern at 20 breaths $/ \mathrm{min}$, with inspiratory time at $33 \%$ of the respiratory cycle, post-inspiratory pause time at $5 \%$ and PEEP at $8 \mathrm{cmH}_{2} \mathrm{O}$. Fractional inspired oxygen $\mathrm{FiO}_{2}$ was 1.0 .

\section{ARDS induction}

Surfactant perturbation was provoked by administration of the detergent dioctyl sodium sulphosuccinate in 5\% aerosol form for 200 breaths, as previously described [20]. Pressure-controlled harmful ventilation was started with a $\mathrm{P}_{\mathrm{PLAT}}$ of 50 $\mathrm{cmH}_{2} \mathrm{O}$ and end-expiratory pressure of $-10 \mathrm{cmH}_{2} \mathrm{O}$ at 10 breaths/min. Dead space was added to maintain normocapnia. Harmful ventilation was continued for 90 min or until compliance $\left(\mathrm{V}_{\mathrm{T}} /\left[\mathrm{P}_{\mathrm{PLAT}}\right.\right.$ - PEEP]) decreased by $25 \%$. Harmful ventilation was stopped when substantial exudates appeared in the tracheal tube. ARDS was diagnosed if arterial oxygen tension $\left(\mathrm{PaO}_{2}\right) / \mathrm{FiO}_{2}$ was less than $27 \mathrm{kPa}$ after 5 min at basal ventilation at PEEP $0 \mathrm{cmH}_{2} \mathrm{O}$. If this criterion was not met, harmful ventilation continued for another $30 \mathrm{~min}$.

Ventilation was continued at $40 \mathrm{breaths} / \mathrm{min}$ and inspiratory:expiratory ratio 1:1 (inspiratory time 30\% + postinspiratory pause time 20\%) while PEEP was slowly increased to 15 $\mathrm{cmH}_{2} \mathrm{O}$. Minute volume was adjusted to reach a $\mathrm{PacO}_{2}$ of 6.0 $\mathrm{kPa}$. Sixty minutes was allowed for stabilization.

\section{Defining the physiological profile and computer simulation of resetting}

Signals from the ventilator and carbon dioxide analyzer representing flow rate, airway pressure, and carbon dioxide concentration at the airway opening were sampled using a personal computer at frequency of $100 \mathrm{~Hz}$ and transferred to a spreadsheet to derive a physiological profile, which is the basis of the computer simulation [17]. In short, the physiological profile consists of 17 parameters describing the elastic pressure/volume curve of the respiratory system, inspiratory and expiratory resistance as a function of volume, and how the volume of eliminated carbon dioxide varies with $V_{T}$ (Figures 1 and 2). $A$ nonlinear elastic pressure/volume curve was constructed, using the following equation: elastic pressure $=a \cdot V^{b}+P E E P$ -

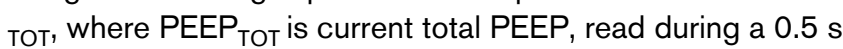
postexpiratory pause while all ventilator valves are closed and no flow exists.

Expired volume of $\mathrm{CO}_{2}\left(\mathrm{~V}_{\mathrm{E}} \mathrm{CO}_{2}\right)$ was described in relation to expired $V_{T}$ (Figure 2) [17]. This gives a first estimate of $V_{E} \mathrm{CO}_{2}$ at a new $V_{\mathrm{T}}$. Carbon dioxide elimination is also dependent on time for gas distribution from the alveolar capillaries up to the fresh gas interface (mean distribution time) [21,22]. Hence, the change in mean distribution time at a new ventilator setting was simulated to obtain a second estimate of $\mathrm{V}_{\mathrm{E}} \mathrm{CO}_{2}$ using data from Uttman and Jonson [21]. The volume of carbon dioxide in the $Y$-piece and adjacent tubing re-inspired during early inspiration $\left(\mathrm{V}_{\mathrm{l}} \mathrm{CO}_{2}\right)$ was calculated [17]. Then, tidal $\mathrm{CO}_{2}$ elimination $\left(\mathrm{V}_{\mathrm{T}} \mathrm{CO}_{2}\right)$ was determined: $\mathrm{V}_{\mathrm{T}} \mathrm{CO}_{2}=\mathrm{V}_{\mathrm{E}} \mathrm{CO}_{2}-\mathrm{V}_{1} \mathrm{CO}_{2}$.

At steady state and at stable metabolic rate, $\mathrm{Paco}_{2}$ is related to the effective alveolar ventilation $[23,24]$. Accordingly, $\mathrm{PaCO}_{2}$ at alternative ventilation was calculated from the effect on RR multiplied byV $\mathrm{T}_{2}$ : 
Figure 1

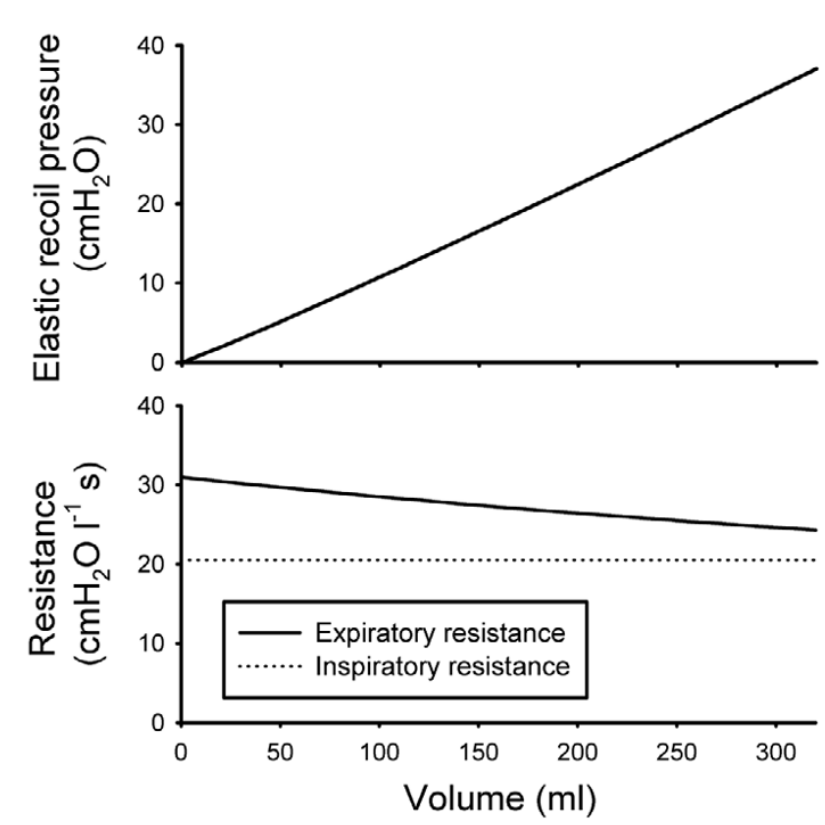

The physiologic profile with regard to mechanics. Elastic recoil pressure (upper) and resistance (lower) as a function of volume above endexpiratory volume at preset total positive end-expiratory pressure.

$\mathrm{PaCO}_{2} \mathrm{PRED}=\mathrm{PaCO}_{2} \cdot \frac{\mathrm{RR} \cdot \mathrm{V}_{\mathrm{T}} \mathrm{CO}_{2}}{\mathrm{RR}_{\mathrm{ALT}} \cdot \mathrm{V}_{\mathrm{T}} \mathrm{CO}_{2} \mathrm{ALT}}$

Where $\mathrm{PaCO}_{2}$ PRED is predicted $\mathrm{PaCO}_{2}$ at alternative respiratory rate $\left(\mathrm{RR}_{\mathrm{ALT}}\right)$ and $\mathrm{V}_{\mathrm{T}} \mathrm{CO}_{2}\left(\mathrm{~V}_{\mathrm{T}} \mathrm{CO}_{2} \mathrm{ALT}\right)$.

\section{Goal-orientated ventilation}

The principle underlying goal-orientated ventilation based on computer simulation has been described elsewhere $[25,26]$. In short, the operator defines the immediate physiological goals that should be achieved by ventilation. Starting from these goals and the physiological profile, the computer iteratively seeks the ventilator setting that is optimal for reaching these goals. In the present context, the simulation goals were defined with the intention being to minimize $\mathrm{V}_{\mathrm{T}}$, maintain normocapnia $\left(\mathrm{Paco}_{2}=6.0 \mathrm{kPa}\right)$, avoid hypoxia $\left(\mathrm{PEEP}_{\mathrm{TOT}} \geq 10\right.$ $\left.\mathrm{cmH}_{2} \mathrm{O}\right)$ and avoid overdistension $\left(\mathrm{P}_{\mathrm{PLAT}}=30 \mathrm{cmH}_{2} \mathrm{O}\right)$.

\section{Minimal $V_{T}$ at high respiratory rate and at ASPIDS}

Simulation was carried out by increasing RR in steps of 5 breaths/min, whereupon the computer iteratively adjusted $V_{T}$ and PEEP so as to achieve the goals. At simulation of each change to the ventilator settings, the following constraints were applied. To avoid the change leading to a nonsignificant reduction in $\mathrm{V}_{\mathrm{T}}$, the $\mathrm{V}_{\mathrm{T}}$ should decrease by at least $0.25 \mathrm{ml}$ for each unit increment in RR. To limit consequences of errors in determination of expiratory resistance, intrinsic PEEP should not be more than $50 \%$ of PEEP TOT. $_{\text {RR was allowed to }}$
Figure 2

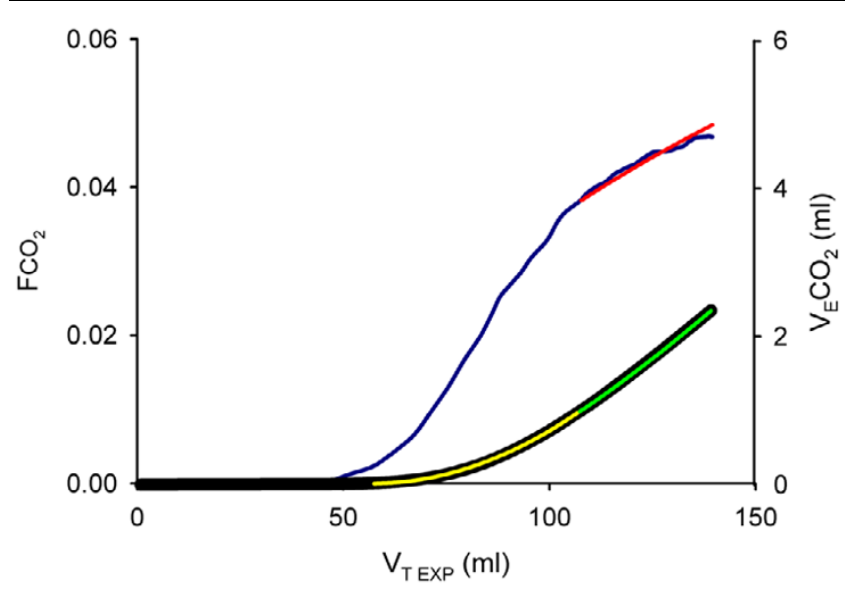

The physiologic profile with regard to carbon dioxide elimination. The blue curve represents carbon dioxide concentration at airway opening $\left(\mathrm{FcO}_{2}\right)$ versus expired tidal volume $\left(\mathrm{V}_{\mathrm{T} \text { EXP }}\right)$. Its upper part was approximated by a logarithmic equation (red curve). Measured expired volume of carbon dioxide $\left(\mathrm{V}_{\mathrm{E}} \mathrm{CO}_{2}\right)$ versus $\mathrm{V}_{\mathrm{TEXP}}$ (black curve) was obtained by integration of the blue curve. To describe $\mathrm{V}_{\mathrm{E}} \mathrm{CO}_{2}$ versus $\mathrm{V}_{\mathrm{TEXP}}$ mathematically, the lower part was expressed as a second-degree polynomial (yellow curve). At high $\mathrm{V}_{\mathrm{T} \text { EXP }}$ the logarithmic equation was integrated (green curve) to allow estimation of $\mathrm{V}_{\mathrm{E}} \mathrm{CO}_{2}$. This mathematical description of $\mathrm{V}_{E} \mathrm{CO}_{2}$ versus $\mathrm{V}_{\mathrm{T} \text { EXP }}$ allows prediction of expired carbon dioxide volumes at an alternative tidal volume.

increase by 20 breaths/min. The iterative simulation used the tool SOLVER in Excel 2003 (Microsoft, Redmond, WA, USA).

The ventilator was reset to achieve the $V_{T}$, PEEP and $R R$ indicated by the simulation. After a stabilization period of $30 \mathrm{~min}-$ utes, a new physiological profile was determined and followed by another simulation. If the latter indicated a significant reduction in $\mathrm{V}_{\mathrm{T}}$, then the ventilator settings were changed and the procedure repeated. The lowest $\mathrm{V}_{\mathrm{T}}$ achieved without ASPIDS was associated with a high respiratory rate $\left(R_{\mathrm{HIGH}_{\mathrm{H}}}\right)$. Then, ASPIDS was simulated using the same constraints as above. The ventilator was reset and ASPIDS was activated during the last $50 \%$ of the expiratory time, using an ASPIDS volume of $0.5 \mathrm{~V}_{\mathrm{T}}+25 \mathrm{ml}$. A physiological profile was established after 30 and $60 \mathrm{~min}$. The volume of gas insufflated in the inspiratory line during the ASPIDS period is a few millilitres higher than the volume of gas simultaneously aspirated from the tip of the tracheal tube. The PEEP regulation of the ventilator efficiently allows the slight surplus of gas to escape without affecting airway pressures. PEEP TOT $_{\text {was measured. }}$

The animals were killed by an overdose of potassium chloride.

\section{Statistical methods}

All data are expressed as mean \pm standard deviation. We used Wilcoxon signed rank test to detect differences in respiratory parameters at different ventilator settings and to determine the accuracy of simulation. 
Table 1

Simulated and measured values at minimal tidal volume

\begin{tabular}{lccccc}
\hline Parameter & \multicolumn{2}{c}{$\mathrm{RR}_{\mathrm{HIGH}}$} & \multicolumn{2}{c}{ ASPIDS } \\
\cline { 2 - 6 } & Simulated & Measured & Simulated & Measured at 30 min & Measured at 60 min \\
\hline $\mathrm{P}_{\mathrm{PLAT}}\left(\mathrm{cmH}_{2} \mathrm{O}\right)$ & 30 & $32 \pm 2.2^{*}$ & 30 & $26 \pm 1.5^{\star \star}$ & $26 \pm 1.4^{\star \star}$ \\
$\mathrm{PEEP}_{\mathrm{TOT}}\left(\mathrm{cmH}_{2} \mathrm{O}\right)$ & $17 \pm 1.8$ & $18 \pm 1.7^{\star}$ & $21 \pm 1.7$ & $17 \pm 2.1^{\star \star}$ & $17 \pm 2.2^{\star \star}$ \\
$\mathrm{PacO}_{2}(\mathrm{kPa})$ & 6.0 & $5.7 \pm 0.70 \mathrm{NS}$ & 6.0 & $5.8 \pm 0.42 \mathrm{NS}$ & $5.7 \pm 0.68 \mathrm{NS}$ \\
\hline
\end{tabular}

Postinspiratory plateau pressure $\left(\mathrm{P}_{\mathrm{PLAT}}\right)$, total positive end-expiratory pressure $\left(\mathrm{PEEP}_{\mathrm{TOT}}\right)$ and arterial carbon dioxide tension $\left(\mathrm{PacO}_{2}\right)$ at lowest tidal volume found in simulation by increasing respiratory rate to high levels (RR $\mathrm{HIIGH}_{\mathrm{H}}$ ) and by using aspiration of dead space (ASPIDS) for 30 and $60 \mathrm{~min}$. Values are expressed as means \pm standard deviation. Differences between measured and simulated values: ${ }^{\star} P<0.05,{ }^{\star \star} P=0.01$. NS, not significant.

\section{Results ARDS model}

The ARDS criterion was met after $54 \pm 29$ min of harmful ventilation. $\mathrm{PaO}_{2} / \mathrm{FiO}_{2}$ was $14 \pm 6.2 \mathrm{kPa}$ at PEEP $0 \mathrm{cmH}_{2} \mathrm{O}$. Physiological dead space was $78 \pm 4 \%$.

\section{Computer simulation}

Under the guidance of simulation, the RR was increased from 40 to $64 \pm 6$ breaths/min as $V_{T}$ was reduced from $7.2 \pm 0.5$ to $6.6 \pm 0.5 \mathrm{ml} / \mathrm{kg}(P=0.005$; Figure 3$)$. At ASPIDS $\mathrm{V}_{\mathrm{T}}$ could, while remaining in accordance with the simulation, be reduced to $4.0 \pm 0.4 \mathrm{ml} / \mathrm{kg}$ at RR of $80 \pm 6$ breaths $/ \mathrm{min}(P=0.005)$. The values for $\mathrm{P}_{\mathrm{PLAT}}$, $\mathrm{PEEP} \mathrm{P}_{\text {TOT }}$ and $\mathrm{PaCO}_{2}$ measured after ventilator resetting to $\mathrm{RR}_{\mathrm{HIGH}}$ and after resetting to ASPIDS for 30 $\min$ and $60 \mathrm{~min}$ were close to those predicted by the simulation (Table 1). However, $\mathrm{P}_{\mathrm{PLAT}}$ and PEEP $\mathrm{TOT}_{\mathrm{TO}}$ were higher than predicted at $\mathrm{RR}_{\mathrm{HIGH}}(P<0.05)$ and lower than predicted at ASPIDS $(P=0.01)$. The fraction of re-inspired carbon dioxide

Figure 3

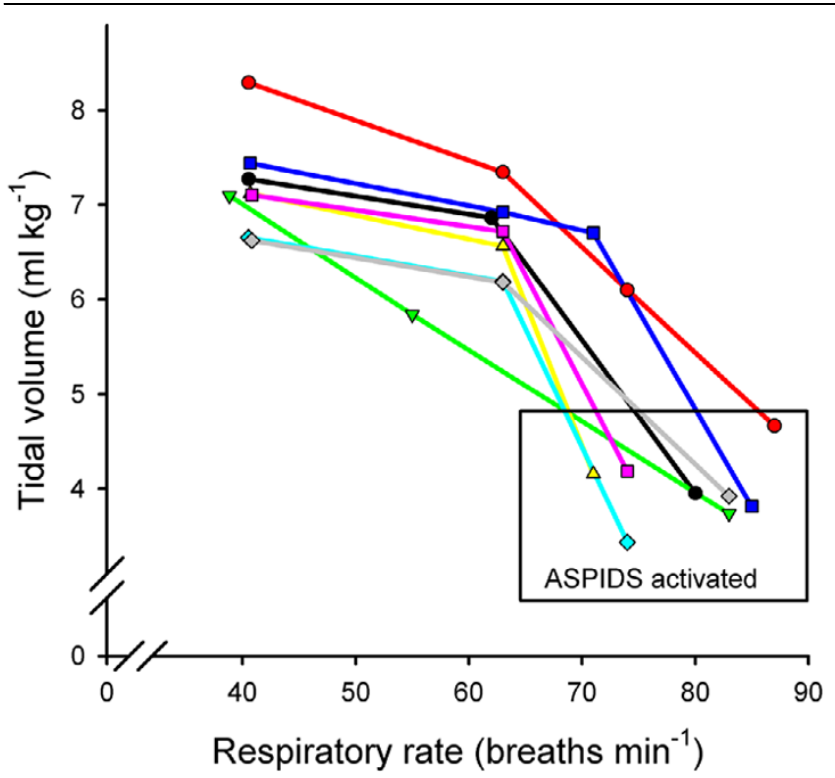

Tidal volume versus respiratory rate. Aspiration of dead space (ASPIDS) allowed an important reduction in tidal volume in all animals.
$\left(\mathrm{V}_{1} \mathrm{CO}_{2} / \mathrm{V}_{\mathrm{E}} \mathrm{CO}_{2}\right)$ increased from $0.29 \pm 0.02$ at 40 breaths $/ \mathrm{min}$ to $0.38 \pm 0.02$ at $\mathrm{RR}_{\mathrm{HIGH}}(P=0.005)$. $\mathrm{PaO}_{2}$ was $66 \pm 10$ at 40 breaths/min and PEEP $15 \mathrm{cmH}_{2} \mathrm{O}$, and did not change at $\mathrm{RR}_{\mathrm{HIGH}}$ or at ASPIDS $(P>0.05)$.

\section{Discussion}

In accordance with the hypothesis, $\mathrm{V}_{\mathrm{T}}$ was reduced at higher RRs but also, and most importantly, when ASPIDS was used. Computer simulation allowed titration of $V_{T}$ as $R R$ was increased and when ASPIDS was used, with satisfactory achievement of goals in terms of airway pressure and gas exchange.

Because this study has its focus on technical and conceptual development, it has several limitations. This porcine ARDS model simulates clinical ARDS with respect to hypoxia. The physiological dead space is increased, as in patients $[27,28]$. Bitzén and coworkers [29] showed that the elastic pressurevolume diagrams demonstrated lung collapse and recruitment, as occur in patients with early ARDS. However, the model may differ from ARDS in patients with sepsis, obstruction and airway secretions. Moreover, in contrast to humans, pigs do not have collateral ventilation that equilibrates ventilatory heterogeneity [30].

Particularly at high RR, gas exchange may therefore differ between the porcine model and clinical ARDS. The concept behind the present study is that a combination of predefined immediate physiological goals should be met by selecting a mode of ventilator operation. Therefore, measurements were limited to 30 and $60 \mathrm{~min}$ after resetting. This time should be long enough for establishment of a new steady state, particularly with respect to $\mathrm{PacO}_{2}$ but not so long that important changes in physiological status of the animal would occur. In a tentative clinical setting, one would need to update the physiological profile at intervals reflecting the stability - or the instability - of the patient. If required, a new simulation should then guide the operator in setting the ventilator with respect to previous or modified goals. Obviously, many more studies will be needed before late outcomes of patients treated on the basis of goal-orientated ventilation can be evaluated. 
Weaning from mechanical ventilation can be facilitated by computer algorithms based on measurements of a few physiological parameters and automatic control of the ventilator [31]. A computerized decision support system for ventilator management may significantly improve patient morbidity in ARDS [32]. These and other previous studies based on computer support aim to improve outcomes using a decision tree based on a few parameters. In the future, computer-supported ventilator setting may be derived from combinations of decision tree algorithms and simulations based on a detailed physiological platform, as in the present study.

In this study one goal was to maintain normocapnia, defined as $\mathrm{PacO}_{2}$ of $6 \mathrm{kPa}$. One could alternatively choose a higher value to follow the principle of permissive hypercapnia. The other goals were to minimise $\mathrm{V}_{\mathrm{T}}$ at a plateau pressure of $30 \mathrm{cmH}_{2} \mathrm{O}$. Taken together, the latter goals imply that PEEP ${ }_{\text {TOT }}$ was maximized. Accordingly, the strategy was based on the concept that lung-protective ventilation is achieved at $P_{\mathrm{PLAT}}$ below 30 $\mathrm{cmH}_{2} \mathrm{O}$, and when repeated collapse and reopening of lung units is minimized by using small $V_{T} s$ and high PEEP. The validity of this concept was not examined in the present study. One could have chosen another strategy to demonstrate the feasibility of goal-orientated ventilation based on iterative computer simulation.

The animals were stabilised at a ventilator setting providing normocapnia at a $P_{\text {PLAT }}$ of $30 \mathrm{cmH}_{2} \mathrm{O}$ at 40 breaths $/ \mathrm{min}$. In spite of the high starting frequency, further gains in terms of a modest but significant reduction in $\mathrm{V}_{\mathrm{T}}$ could be achieved at higher respiratory rates after one or two ventilator resettings based on computer simulation. Accordingly, goal-orientated ventilation by computer simulation is of potential clinical use even when ASPIDS is not applied. The optimal frequency indicated by computer simulation was about 64 breaths/min, which is much higher than usually applied in conventional mechanical ventilation. At $\mathrm{RR}_{\mathrm{HIGH}}$ and at ASPIDS, PEEP was 18 and $17 \mathrm{cmH}_{2} \mathrm{O}$. This was efficient in maintaining lung aeration, as indicated by high $\mathrm{PaO}_{2}$ values. Also, in clinical ARDS an adequate PEEP value is efficient in this respect, even at low $V_{T}[33,34]$. Obviously, dead space is the limiting factor for increasing RR. In mechanical ventilation, re-inspiration of carbon dioxide from the $Y$-piece and adjacent tubing contributes to dead space [35]. At $\mathrm{RR}_{\mathrm{HIGH}}$ this fraction was as high as 0.38 . Another factor that contributes to dead space as a limiting factor for increased RR is that a shorter time for gas distribution and diffusion in the lungs leads to increased dead space $[21,22]$. By incorporating the concept of mean distribution time in the simulation, this factor was brought under control.

When ASPIDS was applied, $\mathrm{V}_{T}$ could, after a single resetting based on computer simulation, be reduced to the very low value of $4 \mathrm{ml} / \mathrm{kg}$, at 80 breaths $/ \mathrm{min}$ on average. Measured $\mathrm{PaCO}_{2}$ agreed with the value predicted by simulation. PEEP and $\mathrm{P}_{\mathrm{PLAT}}$ were lower than predicted. Afterward, we determined that this was due to the reversal of flow in the tracheal tube during ASPIDS, which was not included in the simulation algorithm.

A RR of 80 breaths/min is often referred to the domain of highfrequency ventilation. However, fulfilment of goals at ASPIDS was achieved after simulation based mainly on classical parameters such as resistance, compliance, $V_{\mathrm{T}}$ and dead space. An additional concept was that related to mean distribution time, which is particularly important at high respiratory rates.

Future experimental validation and development may be based on extended study periods comprising multiple resettings. Furthermore, data from routine ventilator resettings in ARDS patients may be used for validation. In this way, the system comprising data analysis of lung function and computer simulation can be validated without any risk to the patient. Another field of development is that of patient safety, but this may be carried out by ventilator manufacturers.

\section{Conclusion}

By applying goal-orientated ventilation based on iterative computer simulation, $\mathrm{V}_{\mathrm{T}}$ could be reduced at high RRs and much more so by applying ASPIDS, while achieving the goals with respect to gas exchange and airway pressure. Classical physiological concepts complemented with that of mean distribution time are valid up to RRs between 60 and 80 breaths $/ \mathrm{min}$. Further studies of long-term effects of ASPIDS, guided by computer simulation, can pave the way for clinical studies in patients with critical lung disease.

\section{Key messages}

- Goal-orientated mechanical ventilation is feasible, using a computer simulation based on a physiological profile.

- Aspiration of dead space allows an important reduction in $\mathrm{V}_{\mathrm{T}}$, with sustained $\mathrm{CO}_{2}$ elimination.

- Studies of long-term effects of aspiration of dead space guided by computer simulation are needed.

\section{Competing interests}

The authors declare that they have no competing interests.

\section{Authors' contributions}

LU participated in study design, data collection, data analysis and manuscript preparation. HÖ participated in data collection, data analysis and manuscript preparation. LN participated in data analysis and manuscript preparation. BD participated in software development and manuscript preparation. BJ participated in study design, data analysis and manuscript preparation. All authors read and approved the final manuscript. 


\section{Acknowledgements}

We thank Gert-Inge Jönsson for construction of the ASPIDS device. We thank the Swedish Heart and Lung Foundation and the Swedish

Research Council (02872) for financial support.

\section{References}

1. Hickling KG, Walsh J, Henderson S, Jackson R: Low mortality rate in adult respiratory distress syndrome using low-volume, pressure-limited ventilation with permissive hypercapnia: a prospective study. Crit Care Med 1994, 22:1568-1578.

2. Amato MB, Barbas CS, Medeiros DM, Magaldi RB, Schettino GP, Lorenzi-Filho G, Kairalla RA, Deheinzelin D, Munoz C, Oliveira R, et al:: Effect of a protective-ventilation strategy on mortality in the acute respiratory distress syndrome. N Engl J Med 1998, 338:347-354.

3. Ranieri VM, Suter PM, Tortorella C, De Tullio R, Dayer JM, Brienza $A$, Bruno F, Slutsky AS: Effect of mechanical ventilation on inflammatory mediators in patients with acute respiratory distress syndrome: a randomized controlled trial. JAMA 1999, 282:54-61.

4. ARDSnetwork: Ventilation with lower tidal volumes as compared with traditional tidal volumes for acute lung injury and the acute respiratory distress syndrome. N Engl J Med 2000, 342:1301-1308

5. Jonson B: Positive airway pressure: some physical and biological effects. In Applied Physiology in Clinical Respiratory Care Edited by: Prakash O. The Hague: Martinus Nihoff Publishers; 1982:125-139.

6. Kallet RH: Evidence-based management of acute lung injury and acute respiratory distress syndrome. Respir Care 2004, 49:793-809.

7. Amato MB, Barbas CS, Medeiros DM, Schettino G, Lorenzi FG, Kairalla RA, Deheinzelin D, Morais C, Fernandes E, Takagaki TY: Beneficial effects of the 'open lung approach' with low distending pressures in acute respiratory distress syndrome. A prospective randomized study on mechanical ventilation. $A m$ J Respir Crit Care Med 1995, 152:1835-1846.

8. Lachmann B: Open up the lung and keep the lung open. Intensive Care Med 1992, 18:319-321.

9. Hickling KG, Henderson SJ, Jackson R: Low mortality associated with low volume pressure limited ventilation with permissive hypercapnia in severe adult respiratory distress syndrome. Intensive Care Med 1990, 16:372-377.

10. Fuhrman BP, Paczan PR, DeFrancisis M: Perfluorocarbon-associated gas exchange. Crit Care Med 1991, 19:712-722.

11. Lunkenheimer PP, Frank I, Ising H, Keller H, Dickhut HH: Intrapulmonary gas exchange during simulated apnea due to transtracheal periodic intrathoracic pressure changes [in German]. Anaesthesist 1973, 22:232-238.

12. Jonson B, Similowski T, Levy P, Viires N, Pariente R: Expiratory flushing of airways: a method to reduce deadspace ventilation. Eur Respir J 1990, 3:1202-1205.

13. De Robertis E, Sigurdsson SE, Drefeldt B, Jonson B: Aspiration of airway dead space. A new method to enhance $\mathrm{CO}_{2}$ elimination. Am J Respir Crit Care Med 1999, 159:728-732.

14. De Robertis E, Servillo G, Jonson B, Tufano R: Aspiration of dead space allows normocapnic ventilation at low tidal volumes in man. Intensive Care Med 1999, 25:674-679.

15. De Robertis E, Servillo G, Tufano R, Jonson B: Aspiration of dead space allows isocapnic low tidal volume ventilation in acute lung injury. Intensive Care Med 2001, 27:1496-1503.

16. Liu YN, Zhao WG, Xie LX, Cao DS, Chen LA, Zhang JP, Zhang B, $\mathrm{Ma} Y M, L i$ YZ, Zhang XG, et al.: Aspiration of dead space in the management of chronic obstructive pulmonary disease patients with respiratory failure. Respir Care 2004, 49:257-262.

17. Uttman $L$, Jonson $B$ : Computer-aided ventilator resetting is feasible on the basis of a physiological profile. Acta Anaesthesiol Scand 2002, 46:289-296.

18. Uttman L, Beydon L, Jonson B: Effects of positive end-expiratory pressure increments can be predicted by computer simulation based on a physiological profile in acute respiratory failure. Intensive Care Med 2003, 29:226-232.

19. Svantesson C, Drefeldt B, Sigurdsson S, Larsson A, Brochard L, Jonson B: A single computer-controlled mechanical insuffla- tion allows determination of the pressure-volume relationship of the respiratory system. J Clin Monit Comput 1999, 15:9-16.

20. Taskar V, John J, Evander E, Robertson B, Jonson B: Surfactant dysfunction makes lungs vulnerable to repetitive collapse and reexpansion. Am J Respir Crit Care Med 1997, 155:313-320.

21. Uttman L, Jonson $B$ : A prolonged postinspiratory pause enhances $\mathrm{CO}_{2}$ elimination by reducing airway dead space. Clin Physiol Funct Imaging 2003, 23:252-256.

22. Aboab J, Niklason L, Uttman L, Kouatchet $A$, Brochard L, Jonson $\mathrm{B}: \mathrm{CO}_{2}$ elimination at varying inspiratory pause in acute lung injury. Clin Physiol Funct Imaging 2007, 27:2-6.

23. Nunn JF, Hill DW: Respiratory dead space and arterial to endtidal carbon dioxide tension difference in anesthetized man. $J$ Appl Physiol 1960, 15:383-389.

24. Taskar V, John J, Larsson A, Wetterberg T, Jonson B: Dynamics of carbon dioxide elimination following ventilator resetting. Chest 1995, 108:196-202.

25. Uttman L: Computer simulation: a tool for optimisation of ventilator setting in critical lung disease. In PhD thesis Lund University, Sweden, Department of Clinical Physiology; 2002.

26. Computer simulation: a tool for optimisation ofventilator setting in critical lung disease [http://www.lub.lu.se/luft/diss/ med 741/med 741.pdf]

27. Beydon L, Uttman L, Rawal R, Jonson B: Effects of positive endexpiratory pressure on dead space and its partitions in acute lung injury. Intensive Care Med 2002, 28:1239-1245.

28. Nuckton TJ, Alonso JA, Kallet RH, Daniel BM, Pittet JF, Eisner MD, Matthay MA: Pulmonary dead-space fraction as a risk factor for death in the acute respiratory distress syndrome. N Engl J Med 2002, 346:1281-1286.

29. Bitzen U, Enoksson J, Uttman L, Niklason L, Johansson L, Jonson $B:$ Multiple pressure-volume loops recorded with sinusoidal low flow in a porcine acute respiratory distress syndrome model. Clin Physiol Funct Imaging 2006, 26:113-119.

30. Woolcock AJ, Macklem PT: Mechanical factors influencing collateral ventilation in human, dog, and pig lungs. J Appl Physiol 1971, 30:99-115.

31. Lellouche $F$, Mancebo J, Jolliet $P$, Roeseler J, Schortgen F, Dojat M, Cabello B, Bouadma L, Rodriguez P, Maggiore S, et al: A multicenter randomized trial of computer-driven protocolized weaning from mechanical ventilation. Am J Respir Crit Care Med 2006, 174:894-900.

32. East TD, Heermann LK, Bradshaw RL, Lugo A, Sailors RM, Ershler L, Wallace CJ, Morris AH, McKinley B, Marquez A, et al.: Efficacy of computerized decision support for mechanical ventilation: results of a prospective multi-center randomized trial. Proc AMIA Symp 1999:251-255.

33. Richard JC, Maggiore SM, Jonson B, Mancebo J, Lemaire F, Brochard L: Influence of tidal volume on alveolar recruitment. Respective role of PEEP and a recruitment maneuver. $\mathrm{Am}$ J Respir Crit Care Med 2001, 163:1609-1613.

34. Richard JC, Brochard L, Vandelet P, Breton L, Maggiore SM, Jonson B, Clabault K, Leroy J, Bonmarchand G: Respective effects of end-expiratory and end-inspiratory pressures on alveolar recruitment in acute lung injury. Crit Care Med 2003, 31:89-92.

35. Fletcher R, Werner O, Nordström L, Jonson B: Sources of error and their correction in the measurement of carbon dioxide elimination using the Siemens-Elema $\mathrm{CO}_{2}$ Analyzer. $\mathrm{Br} J$ Anaesth 1983, 55:177-185. 